\title{
Enacting accountabilities in education: exploring new policy contexts and theoretical elaborations
}

\author{
${\text { Antoni } \operatorname{Verger}^{1} \text { (D) Guri Skedsmo }}^{2,3}$ (D)
}

Accepted: 30 July 2021 / Published online: 26 August 2021

(C) The Author(s), under exclusive licence to Springer Nature B.V. 2021

\section{Introduction}

During the last two decades, education governance has increasingly relied upon performance-based accountability instruments, which national governments have adopted in an attempt to steer growingly fragmented, complex and multi-layered education systems from a distance. Performance-based accountability (PBA) combines data collection instruments - such as external evaluations-with information systems, incentive schemes and/or school support services. Due to their outcomesbased orientation, PBA systems tend to be adopted in parallel with education monitoring tools; learning standards frameworks; school improvement plans; and performance contracts for schools and school actors, such as school leaders and teachers.

However, the costs and benefits of PBA for educational systems are the subject of contentious debate in policy and academic circles. Research on the effects of PBA in education delivery have been inconclusive, largely because PBA policies generate very different reactions in forms of pressure on school actors based on a broad range of policy factors and contextual contingencies. PBA implementation is far from straightforward and does not elicit similar responses throughout educational systems (Lowenhaupt et al., 2016). Even in countries where PBA policies have been implemented for decades, such as the United States (US), studies have identified dissimilar school responses to performance pressure. In general, the implementation of public policies, such as PBA, that explicitly put pressure on actors in an attempt to alter their behaviour is contingent on dynamics of negotiation, sensemaking, persuasion and value conflict (Goodin et al., 2006).

Antoni Verger

antoni.verger@uab.cat

Guri Skedsmo

guri.skedsmo@phsz.ch

1 Department of Sociology, Autonomous University of Barcelona, Cerdanyola, Spain

2 Institute for Research on Professions and Professional Learning, Schwyz University of Teacher Education, Goldau, Switzerland

3 Department of Teacher Education and School Research, University of Oslo, Oslo, Norway 
One of the main objectives of this special issue is to deepen our understanding of the role of sensemaking and enactment theories in PBA research. Enactment theory adds a constructivist current to policy implementation studies that contribute to the field by making sense of how school actors are street-level bureaucrats with a wide room of discretion when it comes to process new policy mandates and put them into practice. Enactment theory has major implications for broader policy analysis and impact studies. Without considering how policy actors interpret and translate policy interventions into practice, it would be less plausible to clarify the nature of the impact of those interventions and identify the mechanisms behind that impact. Unfortunately, most policy impact studies overlook the role of subjective variables and processes of meaning making in the mediation of policy interventions.

Another main objective of this special issue is to contribute to enactment theory through a new wave of research on countries that have been under-analysed from this perspective. Most research on PBA enactment has been conducted in Englishspeaking countries, such as the US, England and Australia, where the predominant configuration of accountability systems is high stakes and aligned to the promotion of market competition between schools. Meanwhile, PBA policies with different characteristics and policy goals have been adopted since the 2000s in regions, such as South America, Asia and the continental and northern parts of Europe, and the enactment and effects of these policies are under-analysed. By publishing the results of new case studies in Chile, Russia, the Netherlands, Italy, Germany, Spain and Norway, this special issue contributes to the territorial diversification of PBA research and offers broader comparative analyses on the role that policy contexts can play in differential PBA enactments.

In this introduction to the special issue, we present the main coordinates of the PBA debate in academic and policy circles and show that the contingent nature of PBA implementation is behind many of the elements of this debate. Then, we demonstrate how enactment theory can contribute to better capture PBA implementation trends in different educational settings, and reflect on the potential of some recent theoretical trends for research in this field. Finally, we present the main contents of this special issue by highlighting how each paper focuses on a different way of enacting PBA in education.

\section{The diverging outcomes of PBA in education: coordinates of a contentious debate}

For education reform advocates, PBA is a source of quality assurance and transparency in public education systems. A key assumption underlying PBA is that holding schools accountable for the achievement of learning standards or their learning progress, and attaching consequences to their degree of success encourages school actors to adopt more effective educational strategies. PBA is to a great extent expected to generate new forms of performative pressure as well as new sources of data that school actors should manage and use to address learning gaps and promote instructional improvement. 
However, evidence on the circumstances and mechanisms under which these policy initiatives generate their intended effects - as well as side effects and unintended effects-remains inconclusive. A number of studies have indicated that standards and accountability have the potential to generate increased awareness and motivation, which can have a positive impact on student achievement (Hanushek \& Raymond, 2005) and lead to the adoption of targeted development strategies and changes in instruction (e.g. Chiang, 2009; Elstad, 2009; Perryman, 2010). Other studies, however, have shown that PBA is conducive to a model of education that places excessive importance on test results (teaching to the test and for the test) and can lead to numerous side effects, including a narrowing of the curriculum and noninclusive educational practices (e.g. Amrein-Beardsley et al., 2010; Au, 2007; Falabella, 2014; Koretz, 2017; Lipman, 2004). To date, evidence on which conditions and mechanisms are most likely to have intended and unintended effects on school actors' practices and behaviours and the teaching profession remains inconclusive.

Paradoxically, PBA policies are advancing internationally despite weak and inconclusive evidence of their benefits. PBA systems were first adopted in the 1980s in countries that embraced neoliberal reforms, such as England, the US and Chile. PBA measures became integrated into those countries as part of a broader reform approach that attempted to introduce outcome-based management and market logics to the delivery of public services. School rankings and league tables were some of the tools that governments used to favour that PBA works to promote market-like relationships within educational systems and results-oriented behaviour in schools.

Since the end of the 1990s, amid the intensification of economic globalisation and the centrality acquired by international large-scale assessments, many other countries started adopting similar policies as a way to monitor and strengthen the competitiveness of their educational systems. In these countries, PBA instruments have travelled as part of broader education reform packages that promote decentralisation, school autonomy and the diversification of school provision (Verger et al., 2019). Concepts, such as the Global Education Reform Movement (Sahlberg, 2016), post-bureaucratic governance in education (Maroy \& Pons, 2019) or New Public Management educational reforms (Gunter et al., 2016), are often used in education literature to capture this international phenomenon.

The very disparate research conclusions on the effects of PBA policies are, to a great extent, a consequence of the diverse nature of PBA systems as well as the diverse institutional and social contexts within which PBA is implemented. PBA can be articulated variously according to how the account-giver is evaluated, by whom and for what purposes; who gives the account exactly; the data sources and metrics; and the consequences of the evaluation results, e.g. high vs low stakes, material vs symbolic effects, individual vs collective consequences (cf. Burke, 2005). These policy design variables, along with contrasting programme ontologies that might prevail behind accountability policies and that also differ by country (see Maroy \& Vosin, 2013), make each PBA system unique.

Beyond policy design variables and initial policy intentions, PBA systems are co-constructed by a range of intermediary and street-level agents, such as local school authorities, teachers and school principals, who are involved in the process of transferring, translating and re-contextualising PBA instruments from the policy 
level to the practice level. The use of such instruments is often enforced by public regulations, such as by being embedded in regulated quality assurance procedures. Through the aforementioned processes, these instruments develop a regulatory status even if they only represent means that aim to fulfil quality assurance.

From the enactment perspective, it is pivotal to understand that PBA systems might differ significantly in terms of how policy actors operating at different levels interpret, re-signify and use PBA-related instruments. According to Skedsmo (2011, p. 7), the effects of these instruments 'depend on how the aims and purposes ascribed to them and the meanings and representations they carry, are perceived, understood and responded to by key actors'. Furthermore, when enacted, PBA instruments have critical interactions with other education policies in place and are particularly sensitive to the socio-economic context of the school and prevailing local education market dynamics. Expectedly, PBA mandates and pressures will be re-signified differently within schools that are at the top of local educational market hierarchies than within schools that are at the bottom; or by schools that operate in turbulent education markets than by schools that operate in relatively stable markets (see Maroy \& van Zanten, 2007). Overall, PBA systems diverge by country and have final outcomes that are highly contingent on a range of local dimensions (Grek et al., 2020).

Overall, the social, educational and institutional effects of PBA instruments are not only mediated by formal regulations and objective indicators, such as the performance category of a school and whether the school is on probation, but also influenced by their creative uses by local school authorities, teachers and school leaders; their articulation with specific instructional or pedagogical strategies and legacies; their legitimation by virtuous goals, such as reducing learning gaps or success for all; and the sense given by educators to such new governance instruments. This is where the policy enactment theory and the PBA conversation intersect. In the next section, we elaborate on the broader theoretical current on policy enactment and demonstrate how focusing on the ways in which school actors view, interpret and translate PBA prerogatives, devices and indicators into daily practices enables social scientists to explore how such instruments can change the goals and behaviour of school actors, especially if they are perceived as having a regulatory status.

\section{Making sense of PBA implementation through policy enactment}

The social, educational and institutional effects of PBA instruments are largely outcomes of the sensemaking processes that these instruments trigger among education actors; their creative uses by local school authorities, school leaders and teachers; and their articulation, including specific instructional or pedagogical strategies and educational legacies in socially situated contexts.

Enactment and sensemaking approaches provide a nuanced understanding of how school actors, e.g. principals and teachers, react to new policy prerogatives and apply them in specific socio-institutional settings (Ball et al., 2011; Braun et al., 2011; Falabella, 2016; Keddie, 2014). These approaches challenge a linear understanding of policy implementation and highlight the contentious and dialectical 
nature of policy processes (Thrupp \& Easter, 2012). These theories conceive educational actors as enjoying a wide degree of discretion in their work, and broadly state that the way these actors interpret and make sense of new policy mandates is key to explaining how such mandates translate into everyday practices (Ball et al., 2011; Spillane et al., 2002).

According to one of the most well-established definitions of policy enactment, enactment processes are comprised of two key moments: interpretation and translation (Braun et al., 2011). Policy interpretation involves individual and collective meaning making dynamics (Louis et al., 2005; Spillane et al., 2002) through which school actors decode external messages and new policy mandates. Principled beliefs, personal biographies, previous experiences or emotional scripts co-constitute the interpretive frames through which educators understand and respond to educational policy (Coburn, 2001, 2005; Reinhorn et al., 2017). Interpretation, beyond an individual action, is a collective process that results from interactions between a broad range of internal (school leaders, teachers, families) and external (inspectors, external consultants, other schools, social networks) stakeholders (Louis et al., 2005; Spillane et al., 2002). Meaning making processes primarily take place within schools, which can be understood as complex micro-political organisations in which competing actors, interests and ideologies may coexist (Bridwell-Mitchell \& Sherer, 2017).

The moment of translation refers to the process through which school actors 'transform their institutional agenda into specific practices, concepts and materials as a means of responding to the policy' (Zancajo, 2020, p. 49). According to Schulte (2018, p. 629), policy translation 'can be selective, picking only those components of a policy that are deemed compatible with the local environment, beneficial in the light of local conditions, or sellable to the local community'. Overall, school actors actively adapt, modify and reframe policy prerogatives to suit their preferences and the needs and constraints of their school's context. Thus, instead of viewing teachers and principals as simple policy-takers, they must be seen as active policy actors and shapers. Teachers and other school actors are street-level bureaucrats (cf. Lipsky, 1993) with potentially sufficient room of manouvre to actively appropriate, negotiate, reframe and resist new policy mandates and adapt external demands to their worldviews and school contexts.

According to the enactment theory, school actors tend to align with new policy mandates when they agree with the policy as well as if they perceive that the reforms can be easily coupled with their previous way of working and/or their particular or collective interests (Malen, 2006). Teachers and principals will predictably dislike a policy if they think it contradicts their professional values, educational beliefs, preexisting notions and/or worldviews (Coburn, 2004). Overall, policy agreement and disagreement and consent and dissent are related to considerations of usefulness, validity and/or fairness. When negative interpretations predominate, schools tend to address the external pressure to comply with new policies and regulations through dilution strategies and obstructive bureaucratic games (Malen, 2006; Maroy \& Pons, 2019).

To contextualise these premises within the accountability debate, school actors who do not believe in the appropriateness of PBA instruments and metrics (or that 
do not see them as reliable and/or fair) would be more inclined to adopt tactics of policy evasion or symbolic responses. Practices, such as teaching to the test in the weeks before test administration, allow educators to preserve their educational orientation while formally, although superficially, complying with external and PBA system requirements. Meanwhile, school actors that view the pressure coming from the PBA system as legitimate would be expected to develop instructional strategies that are more strongly aligned with PBA objectives and their embedded notions of education, such as teacher-centred pedagogies, the delivery of a more fragmented curriculum and the use of performance data to guide school and classroom decisions (Au, 2007; Diamond, 2012).

Sensemaking processes are thus necessary to understand the different responses that schools might articulate when facing PBA pressure. However, it is not always sufficient to capture the polymorphic nature of school responses to external pressures and policy. Recent trends in policy implementation theory encourage the use of a variety of data sources, especially a combination of quantitative and qualitative data, as well as the adoption of theoretical diversity instead of narrow theoretical approaches (see Hupe \& Saetren, 2015). Several authors researching PBA in education have recently joined this current by promoting theoretical cross-fertilisation between enactment and Foucauldian approaches (Ball, 2015; Holloway, 2019), enactment and institutional theory (Maroy \& Pons, 2019; Verger et al., 2020), enactment and multiple accountability perspectives (Benish \& Mattei, 2020; Skedsmo \& Mausethagen, 2016) or enactment combined with network governance and hierarchies (Newman, 2004). Depending on the unit of analysis, enactment perspectives can also be found embedded in studies inspired by system theory approaches that focus on organisational and system responses to accountability (e.g., Strathern, 2000). All these studies show that, beyond interpretation and sense making, other variables and mechanisms (such as the level of perceived performance pressure, the level of tightness-discretion of the accountability system or the presence of several accountability fora with contradicting expectations) are involved in PBA implementation and their varying outcomes. These variables and mechanisms critically interact with prevailing values and belief systems, resulting in cognitive, social and emotional dimensions of accountability enactments.

\section{Articles in this special issue}

The articles in this special issue focus on different ways of enacting PBA in education. They explore how different accountability system designs and configurations are enacted in different contexts and their intended or unintended consequences for the teaching profession and school practices. Special attention is given to the interplay between discourses, actors' strategies and the various enacted policy instruments and their effects on the everyday lives of school actors.

The country cases in the special issue analyse how school actors make sense of, experience and translate new policy demands as well as how they respond to performative pressure and expectations around the use of student performance data and 
the related implications. The variety of cases covered allows for a better understanding of the circumstances and mechanisms that determine different outcomes, educational practices and organisational responses. This variety also reflects how different accountability designs might generate different effects when enacted at district and school levels in diverse institutional and school settings. The analyses cover high-, medium and low-stakes accountability systems, enabling a comparison of various types of accountability regimes that is currently lacking.

The articles look at the implications of PBA for educational equity and quality in different locations. Specifically, the authors reflect on the effects of PBA on educational dimensions, such as teachers' performance, school cooperation, inclusive school practices, teachers' professional autonomy, school curriculum and instructional practices. Furthermore, comparative approaches are applied in order to determine how and to what extent PBA performs differently based on the institutional and socio-economic contexts in which it is implemented. In this sense, the special issue not only explores different forms of PBA enactment but also contributes to broader discussions on the sources of differential enactments between and within countries.

In the first article, Corrie Thiel reports on a comparative study of accountability enactments and possible side effects in four no- and low-stakes contexts in Germany, namely, Berlin, Brandenburg, Thuringia and Rhineland-Palatinate, with a focus on the two states, Berlin and Thuringia, which both represent low-stakes contexts. Although these two states have introduced similar accountability measures, a content analysis of policy documents reveals substantial differences in how accountability is enacted at the federal state level. In addition, analysis of a group discussions among teachers in the two states shows that they seem to perceive, understand and deal with accountabilities differently and that these differences are linked to variations in the enactments at the state level. While side effects are usually associated with high-stakes accountabilities, this study challenges this view.

In the second article, Marjolein Camphuijsen explores how Norwegian principals cope with performative pressure in terms of managing and responding to soft accountability demands and multiple audiences. Based on content analysis of data from interviews with 20 primary school principals, Camphuijsen identifies three distinct response patterns in how principals perceive, interpret and translate PBA demands: alignment, balancing multiple purposes and symbolic responses. This study provides new insights into the policy enactment process and how principals' responses vary according to their views and perspectives on education, the school context and the local accountability regime. As such, the article contributes to an increased understanding of process triggering (side-)effects in a soft and reflexive accountability context.

Despite the growing number of studies on PBA, there is still scarce evidence on how PBA is enacted in socially vulnerable contexts, which usually have to cope with the threat of sanctions and school closures. In the third paper, Lluís Parcerisa addresses this gap by exploring how principals working in disadvantaged schools interpret, experience and enact test-based accountability policies in Chile. Chile is a particularly interesting context for investigating the role of performative pressure on the work of principals and schools since it combines high levels of decentralisation and marketisation with a sophisticated high-stakes accountability system. The study 
has a sequential mixed-methods design, and Parcerisa combines data from surveys administered to principals and teachers and interviews of principals and leadership team members in public and private-subsidised schools with high rates of social vulnerability among their students. Although the PBA system is generally perceived as unfair, the findings show the emergence of new subjectivities and ambivalent narratives that combine appropriation and resistance to PBA. The findings also shed light on mechanisms that explain the adoption of instrumental or expressive responses to PBA in disadvantaged contexts.

In the fourth paper, Natalie Browes addresses accountability enactments by comparing four public schools under the same school board in a small city in the Netherlands: two high performing schools, which are attended by an almost exclusively Dutch middle class population, and two low performing schools, which serve a highly-mixed immigrant population. Different mechanisms encourage different performance orientations within schools, which range from administrative orientations, e.g. the inspectorate, to market orientations, e.g. parents exercising school choice. Through interview data analysis, Browes explores the value that schools and teachers attach to academic performance in general and standardised testing in particular as well as the extent to which teachers experience performance pressure and its impact on their work. The findings show that schools operating within the same governing context, including the same PBA structures, are confronted with quite different challenges. All four schools experience performative pressures; however, the schools experience these pressures in various ways and for various reasons based on how they manoeuvre around and respond to accountability pressures as well as the significance they place on performance.

Test scores and numbers have become key elements in education governance and accountability enactments in terms of providing decontextualised information about the quality of schools. In the fifth paper, Nelli Piattoeva explores how Russian school system actors involved in the production, i.e. policy makers and experts at the national level, or utilisation, e.g. teachers and administrators in one school district, of learning outcomes assessments articulate meaning to the numbers. Through interview data analysis, Piattoeva shows that the actors make sense of the numbers in various ways; state-level actors appreciate the so-called objective nature of the decontextualised information to be used for accountability purposes, while school actors lack the context-related information they need to make use of the data for improvements. The article offers insights on how policy- and school-level actors need more differentiated information to improve educational practices in their particular contexts.

Accountability reforms are intended to make schools, teachers and principals more responsible for their students' results. At the same time, these policy instruments directly impact knowledge construction and practices related to notions of quality and performance. Indeed, school actors have their own agency when interpreting, decoding and translating accountability policy mandates in terms of real school practices. In the sixth paper, Marcel Pagés analyses the meaningmaking process and translation of accountability reforms by school actors from divergent school settings in Madrid, where the regional government has embraced a market-oriented accountability model. Pagés employs a qualitative approach 
based on in-depth interviews with teachers and principals from different school settings and public and private school providers. Participant selection was based on the level of competitive pressure they experience and their schools' positions in the local education market, as expressed in survey responses. Pagés identifies and analyses pedagogical and organisational logics according to the expressive and instrumental strategies of schools, which depend on their position in the local school hierarchy. Consequently, this paper offers new insights on how and why the gap between policy design and policy implementation often persists at the school level.

The diffusion of national standardised testing, large-scale survey assessments and the promotion of self-evaluation policies are making large amounts of data on education systems available and transforming schools into collecting units for a notable range of educational, institutional and socio-economic indicators. Such datafication and the use of related digital technologies for collecting, analysing, retrieving and displaying data activate, at least in principle, new spaces of visibility and forms of school data-based managerialism (Williamson, 2017). While the policy of transparency is oriented towards the development and consolidation of data-based school governance (Selwyn, 2016), its implementation in practice remains an open question. Therefore, investigation of the enactment of school data infrastructures to understand their mobilisation in the governance of schooling is needed. In the seventh paper, Paolo Landri addresses this need by demonstrating how schools can align, imitate and fabricate their data as well as partially and instrumentally use their data, game their data or opt out from the current regime of accountability. The analysis draws on a multi-sited ethnography on the development and consolidation of the digital governance of education in Italy (Landri, 2018) and mobilises a typology of resistance to the digitalisation proposed by Souto-Otero and Beneito-Montagut (2016). Landri demonstrates that schools can align with digital technologies and data or can resist them in many ways.

In the final commentary paper, Jim Spillane explores patterns across the seven empirical papers and reflects on how seemingly similar PBA instruments play out differently in various national, regional and local contexts. In addition, Spillane reflects on ways in which comparisons across the seven studies can be understood. Based on his reading of the papers, Spillane raises several points and considerations for future cross-national research on PBAs and their enactment.

\section{References}

Amrein-Beardsley, A., Berliner, D. C., \& Rideau, S. (2010). Cheating in the first, second, and third degree: Educations' responses to high-stakes testing. Educational Policy Analysis Archives. https:// doi.org/10.14507/epaa.v18n14.2010

$\mathrm{Au}$, W. (2007). High-stakes testing and curricular control: A qualitative metasynthesis. Educational Researcher, 36, 258-267.

Ball, S. J. (2015). What is policy? 21 years later: Reflections on the possibilities of policy research. Discourse: Studies in the Cultural Politics of Education, 36(3), 306-313. https://doi.org/10.1080/01596 306.2015.1015279 
Ball, S. J., Maguire, M., \& Braun, A. (2011). How schools do policy: Policy enactments in secondary schools. Routledge.

Benish, A., \& Mattei, P. (2020). Accountability and hybridity in welfare governance. Public Administration, 98(2), 281-290.

Braun, A., Ball, S. J., Maguire, M., \& Hoskins, K. (2011). Taking context seriously: Towards explaining policy enactments in the secondary school. Discourse: Studies in the Cultural Politics of Education, 32(4), 585-596.

Bridwell-Mitchell, E. N., \& Sherer, D. G. (2017). Institutional complexity and policy implementation: How underlying logics drive teacher interpretations of reform. Educational Evaluation and Policy Analysis, 39(2), 223-247.

Burke, J. C. (2005). Achieving accountability in higher education: Balancing public, academic, and market demands. Jossey-Bass.

Chiang, H. (2009). How accountability pressure on failing schools affects student achievement. Journal of Public Economics, 93(9), 1045-1057.

Coburn, C. E. (2001). Collective sensemaking about reading: How teachers mediate reading policy in their professional communities. Educational Evaluation and Policy Analysis, 23(2), 145-170.

Coburn, C. E. (2004). Beyond decoupling: Rethinking the relationship between the institutional environment and the classroom. Sociology of Education, 77(3), 211-244.

Coburn, C. (2005). Shaping teacher sensemaking: School leaders and the enactment of reading policy. Educational Policy, 19(3), 476-509.

Diamond, J. B. (2012). Accountability policy, school organization, and classroom practice: Partial recoupling and educational opportunity. Education and Urban Society, 44(2), 151-182.

Elstad, E. (2009). Schools which are named, shamed and blamed by the media: School accountability in Norway. Educational Assessment, Evaluation and Accountability, 21(2), 173-189.

Falabella, A. (2014). The performing school: The effects of market and accountability policies. Education Policy Analysis Archives, 22(70), 1-26.

Falabella, A. (2016). Do national test scores and quality labels trigger school self-assessment and accountability? A critical analysis in the Chilean context. British Journal of Sociology of Education, 37(5), 743-760.

Goodin, R. E., Rein, M., \& Moran, M. (2006). The public and its policies. In Moran, M., Rein, M., \& Goodin, R. E. (Eds.). The Oxford handbook of public policy. (pp. 3-35). Oxford University Press.

Grek, S., Maroy, C., \& Verger, A. (2020). Introduction: Accountability and datafication in education: Historical, transnational and conceptual perspectives. In S. Grek, C. Maroy, \& A. Verger (Eds.), World yearbook of education 2021 (pp. 1-22). Routledge.

Gunter, H. M., Grimaldi, E., Hall, D., \& Serpieri, R. (2016). New public management and the reform of education: European lessons for policy and practice. Routledge.

Hanushek, E. A., \& Raymond, M. E. (2005). Does school accountability lead to improved student performance? Journal of Policy Analysis and Management: THe Journal of the Association for Public Policy Analysis and Management, 24(2), 297-327.

Holloway, J. (2019). Teacher evaluation as an onto-epistemic framework. British Journal of Sociology of Education, 40(2), 174-189.

Hupe, P., \& Sætren, H. (2015). Comparative implementation research: Directions and dualities. Journal of Comparative Policy Analysis: Research and Practice, 17(2), 93-102.

Keddie, A. (2014). 'It's like Spiderman... with great power comes great responsibility': School autonomy, school context and the audit culture. School Leadership \& Management, 34(5), 502-517.

Koretz, D. (2017). The testing charade. University of Chicago Press.

Landri, P. (2018). Digital governance of education. Technologies, standards and Europeanization of education. Bloomsbury.

Lipman, P. (2004). High stakes education: Inequality, globalization, and urban school reform. RoutledgeFalmer.

Lipsky, M. (1993). Street-level bureaucracy. Dilemmas of the individual in public services. Russel Sage Foundation.

Louis, K. S., Febey, K., \& Schroeder, R. (2005). State-mandated accountability in high schools: Teachers' interpretations of a new era. Educational Evaluation and Policy Analysis, 27(2), 177-204.

Lowenhaupt, R., Spillane, J. P., \& Hallett, T. (2016). Education policy in leadership practice: "Accountability Talk" in schools. Journal of School Leadership, 26(5), 783-810. 
Malen, B. (2006). Revisiting policy implementation as a political phenomenon: The case of reconstitution policies. In M. I. Honig (Ed.), New directions in education policy implementation: Confronting complexity (pp. 83-104). State University of New York Press.

Maroy, C., \& Pons, X. (2019). Accountability policies in education: A comparative and multilevel analysis in France and Quebec. Springer.

Maroy, C., \& van Zanten, I. A. (2007). Régulation et compétition entre établissements scolaires dans six espaces locaux en Europe. Sociologie Du Travail, 49(4), 464-478.

Maroy, C., \& Vosin, A. (2013). Les transformations récentes des politiques d'accountability en éducation: Enjeux et incidences des outils d'action publique. Educação \& Sociedade, 34(124), 881-901.

Newman, J. (2004). Constructing accountability: Network governance and managerial agency. Public Policy and Administration, 19(4), 17-33.

Perryman, J. (2010). Improvement after inspection. Improving Schools, 13(2), 182-196.

Reinhorn, S. K., Johnson, S. M., \& Simon, N. S. (2017). Investing in development: Six high-performing, high-poverty schools implement the Massachusetts teacher evaluation policy. Educational Evaluation and Policy Analysis, 39(3), 383-406.

Sahlberg, P. (2016). The global education reform movements and its impact on schooling. In K. Mundy, A. Green, B. Lingard, \& A. Verger (Eds.), The handbook of global education policy (pp. 128-144). Wiley Blackwell.

Schulte, B. (2018). Envisioned and enacted practices: Educational policies and the 'politics of use'in schools. Journal of Curriculum Studies, 50(5), 624-637.

Selwyn, N. (2016). 'There's so much data': Exploring the realities of data-based school governance. European Educational Research Journal, 15(1), 54-68.

Skedsmo, G. (2011). Formulation and realisation of evaluation policy: Inconsistencies and problematic issues. Educational Assessment, Evaluation and Accountability, 23(1), 5-20.

Skedsmo, G., \& Mausethagen, S. (2016). Accountability policies and educational leadership-A Norwegian perspective. In J. Easley \& P. Tulowitzki (Eds.), Accountability and educational leadershipCountry perspectives (pp. 205-223). Routledge.

Souto-Otero, M., \& Beneito-Montagut, R. (2016). From governing through data to governmentality through data: Artefacts, strategies and the digital turn. European Educational Research Journal, 15(1), 14-33.

Spillane, J. P., Reiser, B. J., \& Reimer, T. (2002). Policy implementation and cognition: Reframing and refocusing implementation research. Review of Educational Research, 72(3), 387-431.

Strathern, M. (2000). Audit cultures: Anthropological studies in accountability, ethics and the academy. Routledge.

Thrupp, M., \& Easter, A. (2012). Research, analysis and insight into national standards (RAINS) project. University of Waikato.

Verger, A., Fontdevila, C., \& Parcerisa, L. (2019). Reforming governance through policy instruments: How and to what extent standards, tests and accountability in education spread worldwide. Discourse: Studies in the Cultural Politics of Education, 40(2), 248-270.

Verger, A., Ferrer-Esteban, G., \& Parcerisa, L. (2020). In and out of the 'pressure cooker': Schools' varying responses to accountability and datafication. In Grek, S., Maroy, C. \& Verger, A. (eds) World yearbook of education 2021 (pp. 241-261). Routledge.

Williamson, B. (2017). Big data in education: The digital future of learning. Sage.

Zancajo, A. (2020). Schools in the marketplace: Analysis of school supply responses in the Chilean education market. Educational Policy, 34(1), 43-64.

Publisher's Note Springer Nature remains neutral with regard to jurisdictional claims in published maps and institutional affiliations. 